\title{
Health System Redesign to Shift to Hospital Delivery for Maternal and Newborn Survival: Feasibility Assessment in Kakamega County, Kenya
}

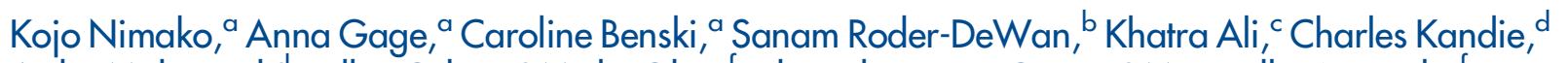

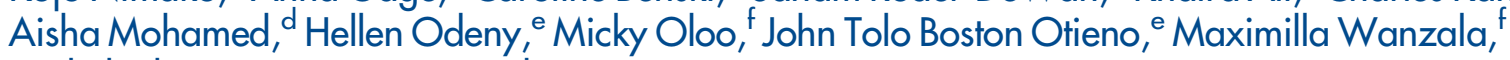
Rachel Okumu, ${ }^{e}$ Margaret E. Kruk ${ }^{a}$

\section{Key Findings}

- Maternal and newborn health service delivery redesign (MNH redesign) is a policy to shift all deliveries to or close to hospitals.

- Current system assets that support MNH redesign in Kakamega County are the adequate geographic spread of hospitals, close proximity of women to these hospitals, and high provider and user support for the concept.

- Before MNH redesign is implemented in Kakamega County, prevailing health system deficits, like health provider shortages and transportation challenges for mothers, would need to be addressed.

\section{Key Implications}

- The county, in partnership with health system researchers, should rigorously evaluate the process of implementing $\mathrm{MNH}$ redesign and its impact on health, to learn and test the model and to serve as a base for generalizing uptake across the country.

- Countries that seek to implement MNH redesign would need to similarly assess feasibility to determine the assets and gaps for implementation.

\footnotetext{
a Department of Global Health and Population, Harvard T.H. Chan School of Public Health, Boston, MA, USA.

b Ifakara Health Institute, Dar es Salaam, Tanzania.

${ }^{c}$ Kenya Council of Governors, Nairobi, Kenya.

${ }^{\mathrm{d} K e n y a}$ Ministry of Health, Nairobi, Kenya.

${ }^{e}$ Kakamega County Department of Health, Kakamega County, Kenya.

fDepartment of Public Health, Masinde Muliro University of Science and Technology, Kakamega County, Kenya.

Correspondence to Kojo Nimako (kojotwumnimako@gmail.com).
}

\section{ABSTRACT}

Maternal and newborn health (MNH) service delivery redesign aims to improve maternal and newborn survival by shiffing deliveries from poorly equipped primary care facilities to adequately prepared designated delivery hospitals. We assess the feasibility of such a model in Kakamega County, Kenya, by determining the capacity of hospitals to provide services under the redesigned model and the acceptability of the concept to providers and users. We find many existing system assets to implement redesign, including political will to improve $\mathrm{MNH}$ outcomes, a strong base of support among providers and users, and a good geographic spread of facilities to support implementation. There are nonetheless health workforce gaps, infrastructure deficits, and transportation challenges that would need to be addressed ahead of policy rollout. Implementing MNH redesign would require careful planning to limit unintended consequences and rigorous evaluation to assess impact and inform scale-up.

\section{INTRODUCTION}

$\mathrm{N}_{\text {many low- and middle-income countries (LMICs), }}^{\text {aternal and newborn mortality remain high in }}$ with these countries accounting for more than $90 \%$ of the global burden. ${ }^{1,2}$ At their current rates of decline, most high-burden countries are unlikely to achieve the Sustainable Development Goals (SDGs) for maternal and child health ${ }^{3}$ despite remarkable increases in facility deliveries. ${ }^{2}$ Recent studies demonstrate that giving birth in a facility does not necessarily translate to improved outcomes, ${ }^{4-6}$ a phenomenon likely attributable to poor quality. More than half of preventable maternal and neonatal deaths in LMICs are estimated to be due to poor quality care during childbirth rather than lack of facility utilization. $^{7}$

Up to $45 \%$ of facility deliveries in LMICs occur in primary care facilities. ${ }^{8,9}$ Many of these primary care facilities lack basic requirements to manage complications arising during delivery, including experienced and specialized staff, supplies, and access to surgical and emergency services, which tend to be available in hospitals. ${ }^{8-10}$ Primary care facilities may also be located far away from advanced care, with limited referral 
options. ${ }^{1-14}$ Thus, improving processes of care in primary care facilities alone is not enough to reduce maternal and newborn mortality. ${ }^{15}$

Against this background, the Lancet Global Health Commission on High Quality Health Systems in the SDG Era (the Quality Commission) proposed service delivery redesign, a reorganization of health systems, to optimize outcomes by ensuring that the right care is provided at the right level of the system and by the right provider. ${ }^{16}$ For maternal and newborn health service delivery redesign (MNH redesign), this reorganization means all births would occur in hospitals that provide dignified, patient-centered care and immediate, definitive care for complications (including capacity for cesarean deliveries, blood transfusion, and care for sick mothers and newborns), or in nearby affiliated birthing facilities. In this model, primary care facilities would focus on providing quality antenatal and postnatal care and would be linked to hospitals where women would deliver. In addition, physical access to facilities would be improved through better transport or upgrading primary care centers to support women in remote communities, and communities would be included in the design of the reorganized system. Details about the components of $\mathrm{MNH}$ redesign, benefits, potential risks, and key implementation considerations have been previously described. ${ }^{17}$

Assessing feasibility is a critical step before embarking on $\mathrm{MNH}$ redesign, not only because redesign is a complex health reform but also because its components must be tailored to the specific needs of the local health system and population.

In this article, we describe a feasibility assessment conducted in Kakamega County, in western Kenya, to determine the capacity of hospitals to provide services under the redesigned model and the acceptability of the concept to providers and users. Kakamega County is the first setting to embark on service delivery redesign as recommended by the Quality Commission.

\section{ASSESSMENT PROCESS}

\section{Understanding the Context}

Kenya has operated a devolved system of governance since 2010, with 47 semiautonomous counties. Kakamega County is one of the most populous, with a population of approximately 2 million people. ${ }^{18}$ Both the maternal mortality ratio in Kakamega, at 316 per 100,000 live births, and the neonatal mortality rate, at 19 per 1,000 live births, are just below Kenya's average (362 for maternal mortality ratio and 22 for neonatal mortality rate) but well above the SDG targets. ${ }^{19,20}$ Kakamega County is among the top 15 counties with the highest burden of maternal mortality in the country. ${ }^{21}$ Kenya will miss the SDG targets for mothers and children at the current rates of decline. ${ }^{3}$

According to health management data from Kakamega County's Department of Health, there were 70,084 estimated deliveries in $2018 ; 35 \%$ of these deliveries occurred at home, $28 \%$ in primary care facilities (dispensaries (Level 2) and health centers (Level 3)), and 37\% in hospitals (Level 4 and 5 facilities). There were 205 facilities in Kakamega County conducting at least 1 delivery in $2018 ; 58 \%$ were very low volume $(<52$ deliveries per year) and accounted for only $5 \%$ of total facility deliveries and $4 \%$ were moderate or high volume (>1000 deliveries per year) and accounted for $48 \%$ of facility deliveries.

Maternal and newborn care in Kenya is provided free of charge in most facilities through the Free Maternity Care (Linda Mama) program. ${ }^{22}$ Kakamega County has also developed the "Imarisha Afya ya mama na Mtoto programpopularly referred to as "Oparanyacare", after the County Governor, Mr. Wycliffe Oparanya, who introduced it - that provides poor and vulnerable women with cash transfers conditional on the use of health facilities for antenatal, delivery, postnatal care and immunization services. ${ }^{23}$

\section{Stakeholder Consultations}

Given the different stakeholders involved in maternal and newborn care, we used a broad and participatory approach for the feasibility assessment. The core study team consisted of individuals from the Kakamega County Department of Health, Kenya Council of Governors, Kenya Ministry of Health, and Harvard University. Consultations were held with health system managers, health care providers, development and implementing partners, health system researchers, and health care users before the start of the assessment to inform its content and strategy. After the analysis stage, we held discussions with the same stakeholder groups to discuss and interpret the findings, identify additional analysis needs, and determine potential strategies for implementation.

\section{Feasibility Assessment Components}

Through consultation, the study team identified 2 broad domains for the feasibility of $\mathrm{MNH}$ redesign in Kakamega County: capacity and acceptability. First, the capacity assessment estimated the geographic proximity of women to delivery care,

\section{For $\mathrm{MNH}$ redesign, a reorganization of health systems means all births would occur in hospitals that provide patient- centered care and immediate care for complications.}




Determining the
feasibility of $\mathrm{MNH}$
redesign in
Kakamega County
involved
assessing capacity
regarding
infrastructure and
human resources
and assessing
acceptability
among health
care providers
and users.

assessed the infrastructure and human resource capacity, and identified potential barriers to care in hospitals. Since the relocation of the place of birth is the biggest change in $\mathrm{MNH}$ redesign, these analyses focused on hospital capacity. Second, we aimed to assess the acceptability of MNH redesign among health care providers and health care users.

There were 5 major components of data collection and analysis, using a mix of primary and secondary data sources.

1. Geographic analysis: We performed a geographic analysis using the following secondary data: facility geolocations were obtained from the Kenya Master Health Facilities List $^{24}$; distribution of pregnancies came from WorldPop 2015 projection $^{25}$; roads and road classification came from OpenStreetMap; ${ }^{26}$ publicly available shapefiles were used to map out the landcover, road characteristics, and the administrative boundaries of the county. The geographic analysis was conducted using the WHO's AccessMod tool. ${ }^{27}$ We estimated the proportion of pregnancies that were within 2 hours, 1 hour, and 30 mins of a delivery facility (now and under redesign) using motorized transport. Details on the assumptions used in the geographic analysis are included in the Supplement.

2. Facility survey: We conducted a facility survey to assess current facility infrastructure and human resource capacity for maternal and newborn care. Data were collected on administration, infrastructure, health workforce, management and data, clinical services, equipment, materials and supplies, and medicines. All 19 hospitals in the county and a stratified random sample of 30 health centers and dispensaries were selected for inclusion in the survey. This analysis focused on the hospitals since they are the key determinants of the feasibility of the MNH redesign program.

3. Self-administered health care provider survey: We conducted a self-administered health care provider survey to assess knowledge and confidence in the management of key maternal and newborn complications and collect provider perspectives on $\mathrm{MNH}$ redesign. A previously validated 60 -item survey for testing knowledge on maternal and newborn care formed the base of the knowledge testrecommended pass score: $80 \% .{ }^{28}$ The survey was adapted to fit the Kenyan context. All doctors, clinical officers, and nurses/midwives providing maternal and newborn care on the day of the facility survey were eligible to take part in the survey. A total of 151 providers completed the survey of 160 eligible (response rate $=94 \%$ ).

4. Gap analysis: Descriptive statistics were calculated on infrastructure and human resource capacity, and we conducted gap analyses to determine future needs under redesign. The estimated number of deliveries was projected for the year 2021 using average year-on-year increase between 2014 and 2019 and holding subcounty delivery proportions constant (Supplement). We assessed 2 scenarios for each item of interest. The "near-term" scenario assumed that all facility deliveries would shift to the designated hospitals, but no home deliveries are shifted. The "long-term" scenario assumed that all deliveries in the county (facility and home births) would shift to the designated hospitals. These gap analyses were done at the facility level, and the assumptions used in estimating the human resource and other needs were based on international guidelines, Kenyan national guidelines, and consultations with subject matter experts in Kenya ${ }^{29-34}$ (full list of assumptions included in the Supplement).

5. Focus group discussions (FGDs): We held 16 community FGDs with 119 participants across 4 sites (details included in the Supplement) to explore practical barriers to receiving quality care, opportunities for better health system utilization, and to obtain perceptions on $\mathrm{MNH}$ redesign. At each site, 1 FGD was held with each of the following groups: (1) women with a recent home delivery; (2) women with a recent facility delivery and other women of reproductive age who have never delivered; (3) mothers-in-law, grandmothers, and traditional birth attendants/birth companions; and (4) husbands and other male community members. A rapid thematic analysis of the discussion notes was done to summarize the FGD findings.

The feasibility assessment, including initial consultations, data collection and analyses, and final consultations, lasted 7 months, from August 2019 to February 2020. As this was a health system quality improvement project, it was deemed exempt from human subject considerations by the Institutional Ethics Review Board of the Masinde 
Muliro University of Science and Technology Department of Public Health and by the Harvard University Office of Human Research Administration. All data used for the assessment were deidentified.

\section{FINDINGS: HOSPITAL CAPACITY IN KAKAMEGA COUNTY}

In consultation with the county health team, the assessment team identified 16 public and faithbased hospitals that could serve as designated delivery hospitals if $\mathrm{MNH}$ redesign is implemented in the county. The county decided to focus on these facilities for planning purposes since they already had oversight or contractual relationships with these facilities. As such 3 private for-profit hospitals, along with their 13 surveyed health care providers, were excluded from this initial analysis. However, exclusion of the 3 private forprofit hospitals in the analysis did not significantly change the results. The 16 hospitals together currently conduct more than half of facility deliveries in Kakamega County and are geographically spread among the 12 subcounties (Figure 1).

\section{Accessibility}

The geographic analysis found that all pregnant women $(100 \%)$ live within 1 hour of travel of current delivery facilities in Kakamega County and 98\% live within 30 minutes. Under $\mathrm{MNH}$ redesign, $100 \%$ of pregnant women would live within 2 hours of travel of a designated hospital, 99\% would live within 1 hour, and 85\% within 30 minutes.

The FGDs identified transportation availability and cost as barriers to reaching hospitals. Lack of transportation was worse at night when motorbike riders feared to respond to calls due to the risk of being robbed (motorbikes being the most common means of transportation in the county). When transportation was available, the prices were sometimes prohibitive at night: a trip that would typically cost $100 \mathrm{KES}$ ( US\$1) during the day may cost 6 times that at night. A few participants indicated that there was sometimes a preference for home deliveries due to the care and attention provided by traditional birth attendants or for cultural reasons, like the need to bury the placenta in the family home. In these few cases, facility access was limited by cultural and social acceptability rather than by distance, cost, or availability of transportation.

\section{Infrastructure}

Table 1 displays the existing infrastructure, gaps, and needs under $\mathrm{MNH}$ redesign in the 16 designated hospitals. Based on standard occupancy rates and average length of stay (Supplement), we estimated that for the current volume of deliveries in the 16 designated facilities, there are currently 120 excess maternity beds, but that 137 additional beds would be required under the near-term service delivery redesign scenario. The 13 currently functional operating rooms are in 7 of the 16 designated hospitals, and 1 operating room for cesarean deliveries would be required in each of the other designated hospitals under both redesign scenarios. Additional blood transfusion and newborn units would also be required. Additional results on infrastructure are provided in the Supplement.

\section{Human Resources}

There are currently substantial gaps in the number of health care providers (Table 1). The prevailing human resource gap suggests a heavy workload for health care providers, and only $63 \%$ of them thought their current workload was manageable. The number of doctors would need to more than triple under the near-term scenario of MNH redesign and the number of nurses/midwives and clinical officers would need to increase 2.5 times to be able to provide care without being overworked. The findings for anesthetists and pediatricians are included in the Supplement.

Beyond the number of staff, we found that health care providers in hospitals had significantly more experience with managing maternal and newborn complications and expressed greater confidence in managing these complications. For example, only $18 \%$ of health care providers in primary care facilities reported managing severe preeclampsia/eclampsia in the preceding 12 months, compared to $82 \%$ of providers in the designated hospitals. However, scores on the knowledge assessment were low across the board. Doctors, who were only found in the hospitals, performed better, with an average score of $68 \%$, albeit still less than the passing score of $80 \%$. Table 2 reports the findings on provider knowledge, experience, and confidence in managing obstetric and newborn complications.

\section{FINDINGS: ACCEPTABILITY OF MNH REDESIGN}

Community members (including mothers and other family members) and health workers expressed high support for service delivery redesign.

From the FGDs with community members, the main potential benefit of redesign identified was that delivery in an improved higher-level facility

\section{The number of doctors would need to more than triple under the near-term scenario of $\mathrm{MNH}$ redesign and the number of nurses/ midwives and clinical officers would need to increase 2.5 times to be able to provide care without being overworked.}


FIGURE 1. Distribution of 16 Hospitals Identified for Delivery Care With Maternal and Newborn Health Service Delivery Redesign, Kakamega County, Kenya

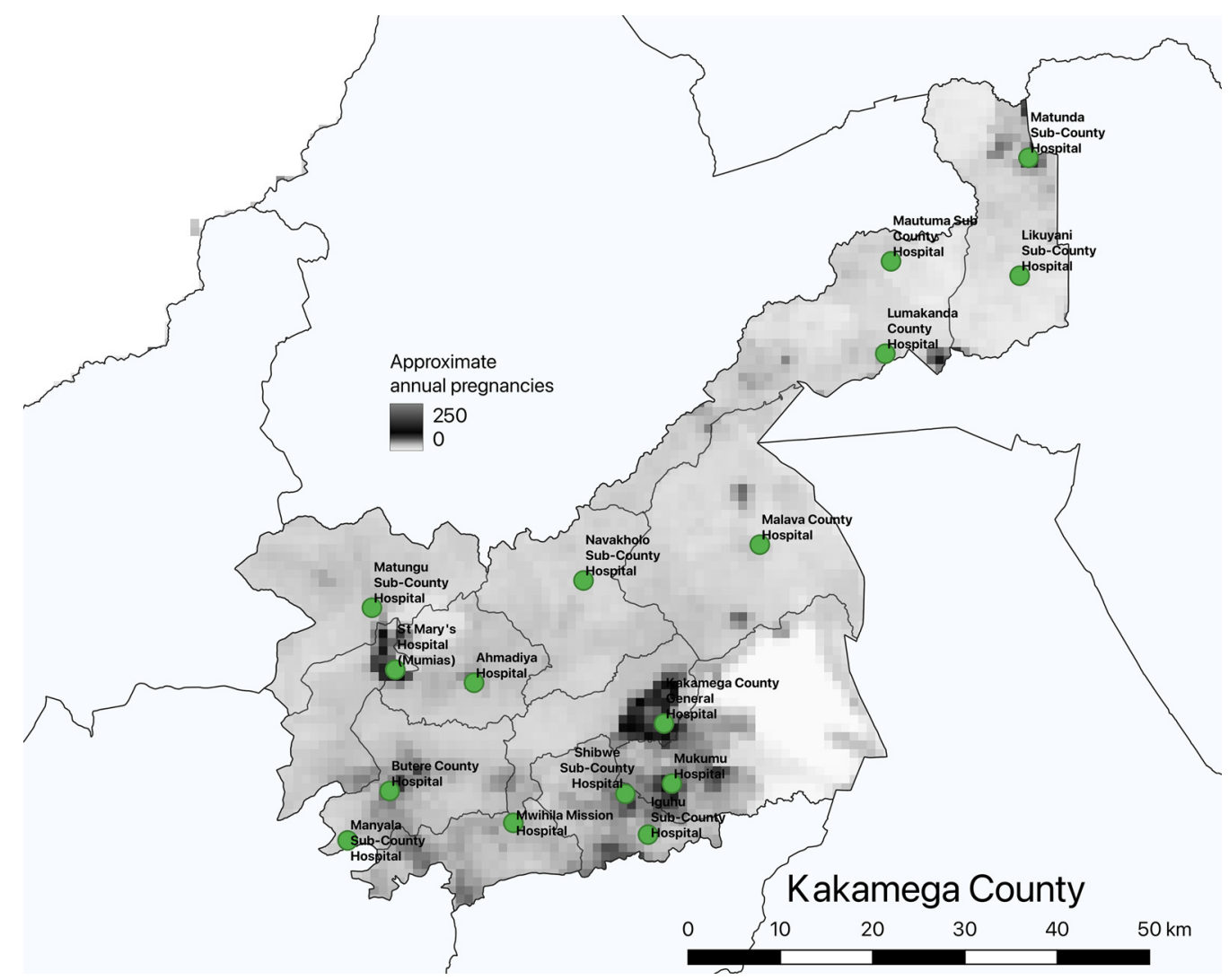

Notes: facility geolocations are from the Kenya Master Health Facilities List ${ }^{24}$ and data on pregnancy densities are from WorldPop (2015). ${ }^{25}$

This assessment shows that hospitals are not distant for most women in Kakamega County, but some women may be excluded from access if concerns about the cost, safety, and ease of reaching a hospital are not addressed. would improve outcomes by reducing the need for referrals. Another potential benefit mentioned was that improving the quality of maternal and newborn care could have a spillover effect on other facility users, e.g., for surgical care. The main challenge identified was transportation because the nearest designated hospital may now be farther away from women. Other concerns were that there may be overcrowding in the designated hospitals, leading to poor-quality care. Many focus group participants identified disrespect, abuse, and lack of patient-centered care as current problems in health facilities, which was sometimes cited as a reason for some mothers preferring to deliver at home (Box).

From the health care provider surveys, approximately $85 \%$ of respondents either strongly agreed or somewhat agreed that $\mathrm{MNH}$ redesign would be more effective in reducing maternal and newborn mortality than the current approach in Kakamega County (Figure 2). Most also believed it would be feasible to implement service delivery redesign in the county.

\section{INTERPRETING THE FINDINGS}

This feasibility assessment found that Kakamega County has a good base of system assets to facilitate a transition to birth in hospitals for all women. There is an adequate distribution of hospitals, health care providers in hospitals demonstrate higher experience with and greater confidence in managing maternal and newborn complications than their counterparts in primary care facilities, and providers and health care users support the idea of MNH redesign. Bottlenecks for $\mathrm{MNH}$ redesign include health care provider deficits, health facility infrastructure inadequacies, and transportation challenges.

This assessment shows that hospitals are not distant for most women in Kakamega County. 
TABLE 1. Current Infrastructural and Human Resource Capacity and Gaps for Redesign Across 16 Designated Hospitals, Kakamega County, Kenya

\begin{tabular}{|c|c|c|c|c|}
\hline & Current Available & Current Gap & $\begin{array}{l}\text { Gap in Near-Term } \\
\text { Redesign Scenario }\end{array}$ & $\begin{array}{l}\text { Gap in Long-Term } \\
\text { Redesign Scenario }\end{array}$ \\
\hline \multicolumn{5}{|l|}{ Infrastructure } \\
\hline Functional operating rooms & 13 & 9 & 9 & 9 \\
\hline Facilities providing blood transfusion & 10 & 6 & 6 & 6 \\
\hline \multicolumn{5}{|l|}{ Human resources } \\
\hline Doctors $^{c}$ & 32 & 25 & 110 & 183 \\
\hline Clinical officers and nurses/midwives & 204 & 183 & 511 & 881 \\
\hline
\end{tabular}

aNear-term scenario is the case where deliveries that would have occurred in a facility (45,440 deliveries) are shifted to the 16 designated hospitals, while longterm scenario is the situation in which all deliveries in Kakamega County, both home and facility $(72,552$ deliveries) are shifted to the 16 redesign facilities. Both scenarios are set in 2021

bThis indicates excess capacity of 120 beds.

Includes medical officers (general practitioners) and obstetrician/gynecologists.

TABLE 2. Health Care Provider Knowledge, Experience, and Confidence in Designated Delivery Hospitals and Sampled Primary Care Facilities, Kakamega County, Kenya

\begin{tabular}{|c|c|c|c|}
\hline & $\begin{array}{c}\text { Health Care Providers in } \\
\text { Primary Care } \\
\text { Facilities }^{a}(n=65)\end{array}$ & $\begin{array}{l}\text { Health Care Providers in } \\
\text { Designated Hospitals }{ }^{b} \\
(n=73)\end{array}$ & $\begin{array}{c}\text { Comparison } \\
{\text { (P Value })^{c}}^{\text {P }}\end{array}$ \\
\hline \multicolumn{4}{|c|}{ Managed complication in past 12 months } \\
\hline Severe pre-eclampsia/eclampsia & $18 \%$ & $82 \%$ & $<.001^{d}$ \\
\hline Obstructed labor & $38 \%$ & $67 \%$ & $.001^{d}$ \\
\hline Newborn resuscitation & $62 \%$ & $89 \%$ & $<.001^{d}$ \\
\hline All 4 complications & $11 \%$ & $59 \%$ & $<.001^{d}$ \\
\hline \multicolumn{4}{|c|}{ Very confident in ability to manage complication } \\
\hline Severe pre-eclampsia/eclampsia & $49 \%$ & $79 \%$ & $<.001^{d}$ \\
\hline Newborn resuscitation & $71 \%$ & $74 \%$ & .674 \\
\hline All 4 complications & $28 \%$ & $45 \%$ & $.033^{d}$ \\
\hline
\end{tabular}

aHealth care providers in primary care facilities include 11 clinical officers and 54 nurses/midwives.

bHealth care providers in the designated hospitals include 9 doctors, 12 clinical officers, and 52 nurses/midwives.

CA 2-sided student t-test was used for the comparison of the knowledge scores and a chi square test was used for the comparison of all the other variables

${ }^{\mathrm{d} A}$ P value $<.05$ indicates statistical significance. 
BOX. Key Participant Quotations in Focus Group Discussions on Maternal and Newborn Service Delivery Redesign in Kakamega, Kenya

When you deliver in the hospital you are more "digital"; you are not "analogue". You are seen to be of high status, and people therefore want to deliver in the facility. - Mother, aged 36 years, with recent home delivery

You would have saved us; it would be very good. If this hospital is set up for delivery, then there would be no delays in accessing care. - Mother, aged 37 years, with a recent home delivery

If that hospital has everything, then you know that you will not be referred to another facility. Every problem will be managed there. You go to [Level 3 facility], there are no drugs, then you go to [non-surgical Level 4 facility] you cannot be helped and then you are sent to CGH (Level 5 facility), and this could take a very long time. -Traditional birth attendant, aged 57 years

Health workers may be a challenge. The health provider may be careless due to overworking. - Mother, aged 39 years, with recent home delivery

Some hope to deliver at home, because at home when you are screaming someone would hold you and support you, but in the facility if you scream no one would come and help you. You do not know anyone in the facility and no one is there to support you. - Mother, aged 28 years, with recent facility delivery

FIGURE 2. Health Care Provider Perceptions on Maternal and Newborn Health Service Delivery Redesign, Kakamega County, Kenya ${ }^{a}$

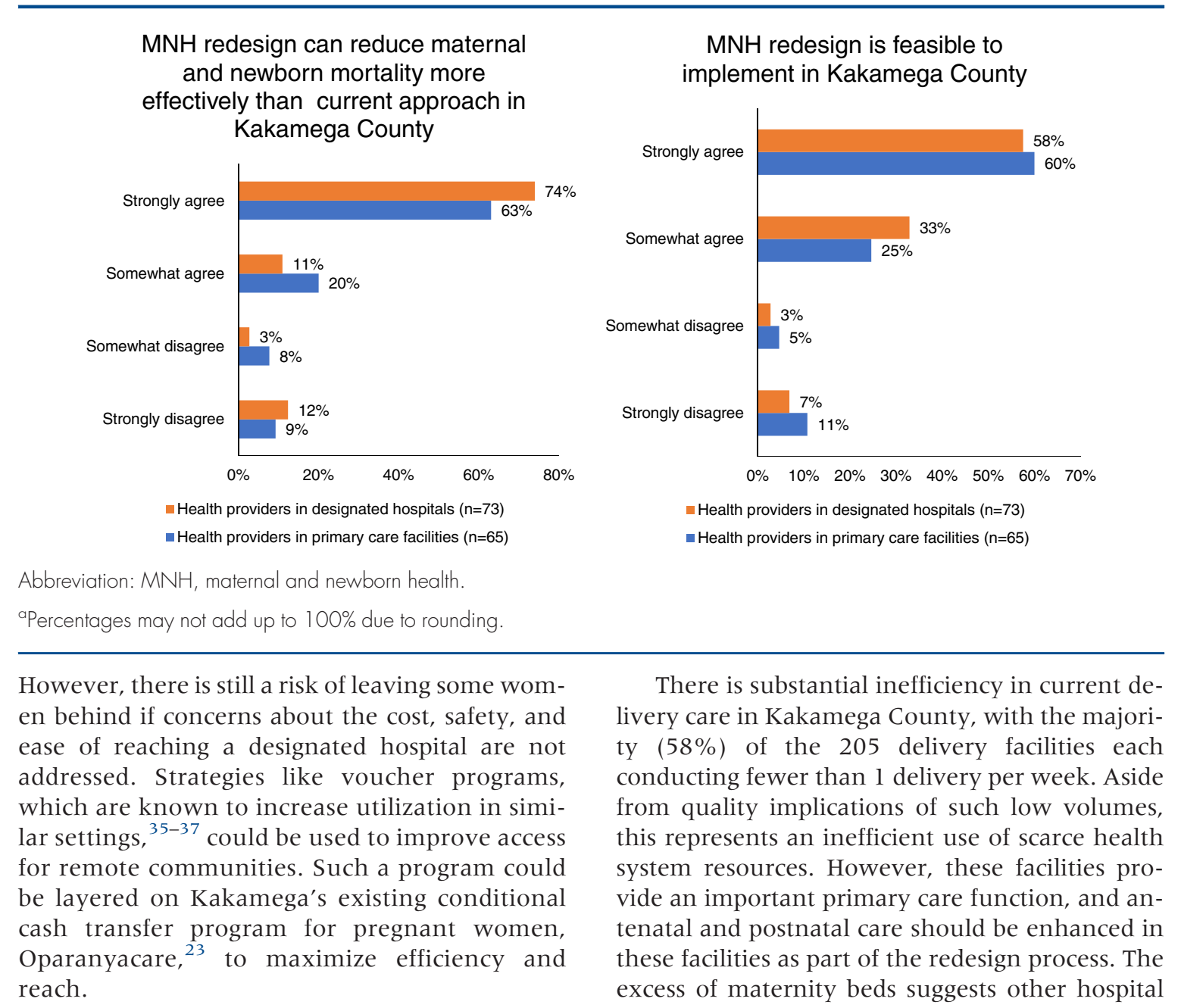


departments may also have similar excesses. If this is the case, a reallocation of these excess beds could reduce the need for new investments with $\mathrm{MNH}$ redesign. Beyond this, most hospitals would require an infusion of critical inputs, including the construction of new or improvements to existing operating theaters and newborn units before $\mathrm{MNH}$ redesign can be rolled out.

Our assessment found significant health worker deficits, both currently and for MNH redesign. Potential sources of new personnel may be to engage doctors on a part-time basis and reassign some of the nurses/midwives in underused primary care facilities, bearing in mind that some may be performing other functions beyond delivery care. $\mathrm{MNH}$ redesign would also result in higher economies of scale for designated hospitals, thus relatively fewer health care providers would be needed. ${ }^{38}$ Based on the low scores observed, provider knowledge and competence would need to be improved. Expert refresher training, specialist supervision, and linkages with obstetric and pediatric training programs may offer a competence boost in the short turn. Since short-term trainings are less durable in sustaining quality and are difficult to scale, ${ }^{39}$ longer-term strategies like reforms to pre-service education would be needed to ensure consistent delivery of quality care.

The FGDs revealed patient concerns about respectful and dignified care in hospitals-a problem that has been highlighted in studies in many LMICs-which is associated with a decreased likelihood of future desire for delivery in the same facility. ${ }^{40-42}$ Respectful, patient-centered care requires policies, training, and investment ahead of the rollout of $\mathrm{MNH}$ redesign to enhance user confidence in the health system.

Two key constituents in the Kakamega health system, health care users and health care providers, demonstrated strong support for MNH redesign. Interestingly, the health care providers at the primary care level were as equally supportive of $\mathrm{MNH}$ redesign as their counterparts in the hospitals, irrespective of the fact that the critical, and in some sense prestigious, function of providing birth care would be shifted away from them. This may be due to well-documented stresses of providing delivery care without sufficient backup. ${ }^{43}$

\section{TAKING A DECISION AND NEXT STEPS}

Upon review of the findings of the feasibility assessment, the Kakamega County government has decided to move forward with planning for and implementing MNH redesign. The county plans to roll out the reform in a phased and deliberate manner, starting with 3 of the 12 subcounties. The decision is primarily driven by the county's ambition to improve outcomes for mothers and newborns, as already demonstrated by the county-level initiative, Oparanyacare. ${ }^{23}$ National policies on free maternal care ${ }^{22}$ and the push toward universal health coverage ${ }^{44}$ are also important supportive contextual factors.

With the decision taken to implement redesign, the next phase of the process is a thorough planning phase. Through this highly participatory planning phase, which includes health system administrators, health care providers, and health care users, and employs a human-centered design approach, the county is outlining the policies, care models, and investments needed to permit the safe rollout of $\mathrm{MNH}$ redesign. This includes developing strategies to increase provider numbers and competence within allowed civil service and county budgeting rules and strategies on how to raise funds internally and align development partner funding for the program. Another key consideration at this stage is how the county can ensure that potential risks of this program, including the risk of overmedicalization of births or reducing access for the very remote, can be prevented. Potential strategies that could reduce the risk of overmedicalization include the utilization of midwife-led birthing centers, which are incorporated in or adjacent to designated delivery hospitals. Strategies to address problems with access could include the provision of free transportation, voucher programs, or the establishment of peoplecentered maternity waiting homes where applicable. With the intended improvement of facilities, another risk is the influx of women from neighboring counties to seek quality birth care in Kakamega county, a situation that can overstretch the infrastructure and health care providers. The county would need to closely monitor delivery volumes when the program is rolled out and prepare a plan to address overutilization. Program costing will also occur at this planning stage; the costing has been completed for the first phase (first 3 subcounties) of implementation. After this planning phase, there will be an improvement phase to address quality, access, and capacity gaps. In this phase, actual health system improvements (in infrastructure, human resource capacity, access, and other sectors) will be undertaken to ensure that the system is ready to support the service delivery redesign program. Only then, after the system has been adequately prepared, would the redesign

\section{Another key consideration at the planning stage is how the county can prevent potential risks, including the risk of over- medicalization of births or reducing access for the very remote.}


MNH redesign is not a one-sizefits-all policy; this makes a feasibility assessment a necessary first step in the process. policy be rolled out and mothers be encouraged to deliver in designated hospitals. There is also a plan for the process of implementation and the impact of redesign to be rigorously evaluated, to inform scale-up outside of Kakamega County.

Kakamega County has committed to funding recurring costs of the program and has aligned donor funding for the capital costs of the first phase of implementation. With fiscal space already constrained and the COVID-19 pandemic redirecting funds toward emergency preparedness, inadequate funding may delay the scaleup of redesign. Donor inflows are also dwindling due to the gravitation toward self-reliance in Kenya, which means most of the future infrastructural and human resource improvements would be borne by the county government. However, this is an opportunity for the county to consider the role of the private sector in the provision of health care and to potentially include them in the redesign process as it evolves.

\section{Limitations}

This feasibility assessment had several limitations. First, at the time the feasibility assessment concluded, no costing was included because the price tag of the policy shift depends on the specific solutions the county chooses to address the identified gaps. However, a detailed costing of the first phase of the redesign program has subsequently been completed as part of the planning process to implement redesign. The cost of $\mathrm{MNH}$ redesign was of interest to many stakeholders during the consultations at the end of the feasibility assessment and future feasibility assessments should thus consider including some costing for key identified gaps. Second, knowledge assessments and selfadministered questionnaires may overestimate skills, and as such, the results of the health care provider assessments need to be considered in the context of mortality and morbidity outcomes and patient-reported outcomes. Where possible, future assessments can consider including observations of service provision to better judge health care provider skills. Lastly, while we conducted a stakeholder assessment with key decision makers in Kakamega County, a broader stakeholder engagement/analysis would be important to better understand the political support for and opposition to redesign.

\section{CONCLUSION}

This feasibility assessment has shown that Kakamega County is ready for $\mathrm{MNH}$ redesign: there is political goodwill to improve maternal and newborn health outcomes, a strong base of stakeholder support, and a good spread of facilities to support implementation. There are nonetheless a health workforce gap, infrastructure deficits, and transportation challenges that would need to be addressed ahead of policy rollout.

This feasibility assessment also shows that there is latent capacity in LMICs to institute systems-level change to accelerate progress toward achieving the SDGs. However, redesign is not a one-size-fits-all policy and will look different in different settings. This makes a feasibility assessment a necessary first step. The feasibility assessment methodology presented in this article provides a blueprint for adaptation for countries that seek to embark on $\mathrm{MNH}$ redesign.

Acknowledgments: We are grateful to the following individuals for their contributions to the feasibility assessment: Dr. Edward Serem and Dr. Clarice Okumu, at the Kenya Ministry of Health, for assisting with the adaptation of the health care provider knowledge survey to the Kenyan context; Ms. Meboh Abuor and Ms. Maureen Khaniri, at the Kenya Council of Governors, for their assistance with stakeholder engagements; Mr. Mike Ruto and Ms. Janet Anyenda, at the Kakamega County Department of Health, for providing support for data extraction from the county's health management information system; Dr. Hannah Leslie and Ms. Min Kyung Kim, at the Harvard T.H. Chan School of Public Health, for assistance with data analysis; and Ms. Purity Kamande, Mr. Nicholas Ochieng Mandela, Mr. Donald Ochieng and Mr. Patrick Kukubo Walukhu for assisting with data collection. We also appreciate the efforts of all the officials of the Kenya Ministry of Health, Kenya Council of Governors, and Kakamega County Department of Health who worked behind the scenes to ensure the success of the assessment. We finally thank all the stakeholders and study participants who availed themselves and cooperated with the study team to provide critical data and insights into the Kakamega and Kenya health system.

Funding: This work was supported in whole by the Bill \& Melinda Gates Foundation [INV-009995].

Author contributions: KN, AG, SRD, KA, CK, AM, JTBO, RO, and MEK jointly conceptualized the program in Kakamega County. KN, AG, SRD, $\mathrm{HO}, \mathrm{MO}, \mathrm{MW}$, and MEK developed the instruments used for data collection. KN, KA, CK, HO, MO, and MW led the data collection. KN $A G, C B, S R D$, and $M E K$ conducted the data analysis. $K N, A G$ and $C B$ wrote the first draft of the manuscript; all authors reviewed and edited the draft. All authors read and approved the final manuscript.

Competing interests: None declared.

\section{REFERENCES}

1. Alkema L, Chou D, Hogan D, et al. Global, regional, and national levels and trends in maternal mortality between 1990 and 2015 with scenario-based projections to 2030: a systematic analysis by the UN Maternal Mortality Estimation Inter-Agency Group. Lancet. 2016;387(10017):462-474. CrossRef. Medline

2. Boerma T, Requejo J, Victora CG, et al. Countdown to 2030: tracking progress toward universal coverage for reproductive, maternal, newborn, and child health. Lancet. 2018;391(10129):1538-1548. CrossRef. Medline

3. McArthur JW, Rasmussen K, Yamey G. How many lives are at stake? Assessing 2030 sustainable development goal trajectories for maternal and child health. BMJ. 2018;360:k373. CrossRef. Medline 
4. Kunkel M, Marete I, Cheng ER, et al. Place of delivery and perinatal mortality in Kenya. Sem Perinatol. 2019;43(5):252-259. CrossRef. Medline

5. Gabrysch S, Nesbitt RC, Schoeps A, et al. Does facility birth reduce maternal and perinatal mortality in Brong Ahafo, Ghana? A secondary analysis using data on 119244 pregnancies from two cluster-randomised controlled trials. Lancet Glob Health. 2019;7(8): e1074-e1087. CrossRef. Medline

6. Fink G, Ross R, Hill K. Institutional deliveries weakly associated with improved neonatal survival in developing countries: evidence from 192 Demographic and Health Surveys. Int J Epidemiol. 2015;44 (6): 1879-1888. CrossRef. Medline

7. Kruk ME, Gage AD, Joseph NT, Danaei G, García-Saisó S, Salomon JA. Mortality due to low-quality health systems in the universal health coverage era: a systematic analysis of amenable deaths in 137 countries. Lancet. 2018;392(10160):2203-2212. CrossRef. Medline

8. Campbell OMR, Calvert C, Testa A, et al. The scale, scope, coverage, and capability of childbirth care. Lancet. 2016;388(10056):21932208. CrossRef. Medline

9. Kruk ME, Leslie HH, Verguet S, Mbaruku GM, Adanu RMK, Langer A. Quality of basic maternal care functions in health facilities of five African countries: an analysis of national health system surveys. Lancet Glob Health. 2016;4(11):e845-e855. CrossRef. Medline

10. Kozuki N, Oseni L, Mtimuni A, et al. Health facility service availability and readiness for intrapartum and immediate postpartum care in Malawi: a cross-sectional survey. PLoS One. 2017;12(3): e0172492. CrossRef. Medline

11. Elmusharaf K, Byrne E, AbuAgla A, et al. Patterns and determinants of pathways to reach comprehensive emergency obstetric and neonatal care (CEmONC) in South Sudan: qualitative diagrammatic pathway analysis. BMC Pregnancy Childbirth. 2017;17(1):278. CrossRef. Medline

12. Hirose A, Borchert M, Cox J, Alkozai AS, Filippi V. Determinants of delays in travelling to an emergency obstetric care facility in Herat, Afghanistan: an analysis of cross-sectional survey data and spatial modelling. BMC Pregnancy Childbirth. 2015;15(1):14. CrossRef. Medline

13. Shamba D, Tancred T, Hanson C, Wachira J, Manzi F. Delayed illness recognition and multiple referrals: a qualitative study exploring care-seeking trajectories contributing to maternal and newborn illnesses and death in southern Tanzania. BMC Health Serv Res. 2019;19(1):225. CrossRef. Medline

14. Niyitegeka J, Nshimirimana $G$, Silverstein A, et al. Longer travel time to district hospital worsens neonatal outcomes: a retrospective crosssectional study of the effect of delays in receiving emergency cesarean section in Rwanda. BMC Pregnancy Childbirth. 2017;17(1):242. CrossRef. Medline

15. Semrau KEA, Hirschhorn LR, Marx Delaney M, et al. Outcomes of a coaching-based WHO Safe Childbirth Checklist program in India. N Engl J Med. 2017;377(24):2313-2324. CrossRef. Medline

16. Kruk ME, Gage AD, Arsenault $C$, et al. High-quality health systems in the Sustainable Development Goals era: time for a revolution. Lancet Glob Health. 2018;6(1 1):e1 196-e1252. CrossRef. Medline

17. Roder-DeWan S, Nimako K, Twum-Danso NAY, Amatya A, Langer $A$, Kruk M. Health system redesign for maternal and newborn survival: rethinking care models to close the global equity gap. $B M$ Glob Health. 2020;5(10):e002539. CrossRef. Medline

18. Kenya open data. Kenya National Bureau of Statistics. Accessed October 28, 2021. https://knbs.or.ke/visualizations/

19. Sustainable Development Goals. United Nations. Accessed October 28, 2021. https://sdgs.un.org/goals

20. Kenya National Bureau of Statistics, Ministry of Health, the National AIDS Control Council (NACC), the National Council for Population and Development (NCPD), and the Kenya Medical Research Institute (KEMRI). Kenya Demographic and Health Survey 2014. Kenya National Bureau of Statistics; 2014. Accessed October 28, 2021. https://dhsprogram.com/pubs/pdf/fr308/fr308.pdf

21. United Nations Population Fund (UNFPA). Summary Report of the Assessment of UNFPA's Advocacy Campaign to End Preventable Maternal and Newborn Mortality in Kenya. UNFPA; 2016. Accessed October 28, 2021. https://kenya.unfpa.org/sites/ default/files/pub-pdf/UNFPA\%2ORMNCAH\%20Advocacy\% 20Campaign\%20Assessment\%20Summary\%5BTo\%20Print\%5D.pdf

22. Linda Mama services. National Hospital Insurance Fund. Accessed October 28, 2021. https://blog.nhif.or.ke/website/linda-mamahospitals/

23. For love of family, Imarisha Afya ya Mama na Mtoto. Accessed October 28, 2021. http://www.oparanyacare.com

24. Kenya Master Health Facility List. Accessed October 28, 2021. http://kmhfl.health.go.ke/\#/home

25. Open spatial demographic data and research. Accessed October 28, 2021. https://www.worldpop.org/

26. OpenStreetMap. Accessed October 28, 2021. https://www. openstreetmap.org/\#map=4/38.01/-95.84

27. AccessMod 5. Accessed October 28, 2021. https://www. accessmod.org/

28. Kruk ME, Galea S. External Evaluation of Saving Mothers Giving Life. Final Report. Saving Mothers Giving Life; 2013. Accessed October 28, 2021. https://www.publichealth.columbia.edu/sites/default/ files/legacy/smgl-report.pdf

29. Republic of Kenya Ministry of Health (MOH). Division of Health Sector Monitoring and Evaluation. Kenya Harmonized Health Facility Assessment (KHFA): 2018/2019. MOH; 2019. Accessed October 28, 2021. hitps://open. africa/dataset/4f4a9bae-5af9447b-bd00-fa 13869070a0/resource/cac4a9a8-9330-45d39c31-ff2302543589/download/khfa-2018-19-annex-tables-final. pdf

30. Kaye DK, Kakaire O, Osinde MO. Systematic review of the magnitude and case fatality ratio for severe maternal morbidity in subSaharan Africa between 1995 and 2010. BMC Pregnancy Childbirth. 2011;11(1):65. CrossRef. Medline

31. Republic of Kenya Ministry of Health (MOH). Health Infrastructure Norms and Standards. MOH; 2017.

32. Murphy GAV, Waters D, Ouma PO, et al. Estimating the need for inpatient neonatal services: an iterative approach employing evidence and expert consensus to guide local policy in Kenya. BM Glob Health. 2017;2(4):e000472. CrossRef. Medline

33. Tsiachristas A, Gathara D, Aluvaala J, Chege T, Barasa E, English M. Effective coverage and budget implications of skill-mix change to improve neonatal nursing care: an explorative simulation study in Kenya. BM Glob Health. 2019;4(6):e001817. CrossRef. Medline

34. Murphy GAV, Gathara D, Abuya N, et al. What capacity exists to provide essential inpatient care to small and sick newborns in a high mortality urban setting? - A cross-sectional study in Nairobi City County, Kenya. PLoS One. 2018;13(4):e0196585. CrossRef. Medline

35. Massavon W, Wilunda $C$, Nannini $M$, et al. Effects of demand-side incentives in improving the utilisation of delivery services in Oyam District in northern Uganda: a quasi-experimental study. BMC Pregnancy Childbirth. 2017;17(1):431. CrossRef. Medline

36. Bellows B, Kyobutungi C, Mutua MK, Warren C, Ezeh A. Increase in facility-based deliveries associated with a maternal health voucher programme in informal settlements in Nairobi, Kenya. Health Policy Plan. 2013;28(2):134-142. CrossRef. Medline

37. Hunter BM, Harrison S, Portela A, Bick D. The effects of cash transfers and vouchers on the use and quality of maternity care services: a 
systematic review. PLoS One. 2017:12(3):e0173068. CrossRef. Medline

38. Stones W, Visser GHA, Theron G, et al. FIGO Statement: Staffing requirements for delivery care, with special reference to low- and middle-income countries. Int J Gynaecol Obstet. 2019;146(1):3-7. CrossRef. Medline

39. Rowe AK, Rowe SY, Peters DH, Holloway KA, Chalker J, Ross-Degnan D. Effectiveness of strategies to improve health-care provider practices in low-income and middle-income countries: a systematic review. Lancet Glob Health. 2018;6(1 1):e1 163-e1 175. CrossRef. Medline

40. Bohren MA, Vogel JP, Hunter EC, et al. The mistreatment of women during childbirth in health facilities globally: a mixed-methods systematic review. PLoS Med. 2015;12(6):e1001847, discussion e1001847. CrossRef. Medline
41. Abuya T, Warren CE, Miller N, et al. Exploring the prevalence of disrespect and abuse during childbirth in Kenya. PLoS One. 2015;10 (4):e0123606. CrossRef. Medline

42. Kujawski S, Mbaruku G, Freedman LP, Ramsey K, Moyo W, Kruk ME. Association between disrespect and abuse during childbirth and women's confidence in health facilities in Tanzania. Matern Child Health J. 2015;19(10):2243-2250. CrossRef. Medline

43. Engl $E$, Kretschmer $S$, Jain $M$, et al. Categorizing and assessing comprehensive drivers of provider behavior for optimizing quality of health care. PLoS One. 2019;14(4):e0214922. CrossRef. Medline

44. Kenya rolls out Universal Health Coverage. News release. World Health Organization Regional Office for Africa; December 23 2018. Accessed November 12, 2021. https://www.afro.who.int/ news/kenya-rolls-out-universal-health-coverage

Peer Reviewed

Received: October 23, 2020; Accepted: September 22, 2021; First published online: November 30, 2021.

Cite this article as: Nimako K, Gage A, Benski C, et al. Health system redesign to shift to hospital delivery for maternal and newborn survival: feasibility assessment in Kakamega County, Kenya. Glob Health Sci Pract. 2021;9(4):1000-1010. https://doi.org/10.9745/GHSP-D-20-00684

(c) Nimako et al. This is an open-access article distributed under the terms of the Creative Commons Attribution 4.0 International License (CC BY 4.0), which permits unrestricted use, distribution, and reproduction in any medium, provided the original author and source are properly cited. To view a copy of the license, visit https://creativecommons.org/licenses/by/4.0/. When linking to this article, please use the following permanent link: https:// doi.org/10.9745/GHSP-D-20-00684 